\title{
Recovery Mechanisms in a Compressed Ni-Ti Superelastic Alloy
}

\author{
Shimeni Baptista Daer *, Andersan Paula ${ }^{b}$, Luiz Carlos Almeida Vieira ${ }^{c}$, Edir Neves Teixeira, \\ Jorge Otubo ${ }^{d}$, Francisco Manuel Braz Fernandes ${ }^{e}$ \\ ${ }^{a}$ Centro Universitário de Volta Redonda, Volta Redonda, RJ, Brazil \\ ${ }^{b}$ Instituto Militar de Engenharia, Rio de Janeiro, RJ, Brazil \\ ${ }^{c}$ Universidade Federal Fluminense, Volta Redonda, RJ, Brazil \\ ${ }^{d}$ Instituto Tecnológico da Aeronáutica, São José dos Campos, SP, Brazil \\ ${ }^{e}$ CENIMAT/i3N, Departamento de Ciência dos Materiais, Faculdade de Ciências e Tecnologia, \\ Universidade Nova de Lisboa, 2829-516, Caparica, Portugal
}

Received: May 26, 2017; Revised: August 29, 2017; Accepted: September 17, 2017

The present work studied the influence of annealing on a $\mathrm{Ni}$-Ti alloy submitted to uniaxial compression. The stress-strain curve under compression showed the absence of the Stress-InducedMartensite (SIM) plateau and $42 \%$ of remaining austenitic phase (B2). identified by the Electron Backscattered Diffraction (EBSD) technique on a Scanning Electronic Microscope (SEM). Annealing at $150{ }^{\circ} \mathrm{C}$ increased the volume fraction of austenite to $70 \%$. Annealing at $200{ }^{\circ} \mathrm{C}$ reduced the volume fraction of austenite to $33 \%$ and increased the classical Vickers hardness and the dynamic elastoplastic hardness. This increase suggests the presence of a phase with higher indentation resistance, which can be the R phase reported in the literature. Annealing at $250{ }^{\circ} \mathrm{C}$ decreased the classical Vickers hardness and the dynamic elastoplastic hardness, probably due to recovery. Annealing at $300^{\circ} \mathrm{C}$ advanced the recovery process and promoted some recrystallization, as suggested by the large standard deviation observed in the hardness results.

Keywords: Nitinol, compression, recovery, ultramicrohardness, EBSD

\section{Introduction}

Nearly equiatomic nickel-titanium alloys assumed considerable importance since their discovery in the 60's, due to properties such as shape memory and superelasticity ${ }^{1}$.

These alloys have an interface between a martensitic monoclinic phase (B19') and a high-temperature austenitic phase (B2), positioned in such a way that the shear stress is smaller than the value required to promote slip. These variants have an invariant plane and lead to the B19' $\rightarrow$ B2 transformation along a fixed path. The existence of a transformation path with negligible plastic deformation makes the phenomenon reversible until dislocation slip occurs ${ }^{2,3}$.

The typical phenomenon of recovery consists of mutual annihilation of dislocations; this leads to hardness reduction and ductility increase by nucleation and growth of non-strain hardened grains. For alloys that undergo a thermoelastic martensitic transformation, the influence of thermal activation and defect annihilation on the recovery of shape memory and superelasticity is still relatively unknown ${ }^{4}$.

Previous studies ${ }^{4}$ showed that recovery occurs in two steps (B19' $\rightarrow \mathrm{R} \rightarrow \mathrm{B} 2$ ). Also, there was evidence of dislocation polygonization during what can be called recovery (as in conventional alloys ${ }^{5}$ ). Recently, the reverse transformation $\left(\mathrm{B} 19^{\prime} \rightarrow \mathrm{B} 2\right.$ ) was proposed as an explanation for the recovery

*e-mail: shimeni@gmail.com of alloys with transformation suppression due to previous deformation ${ }^{4}$. During nucleation and growth of new grains, one can still observe the presence of residual stress due to previous deformation ${ }^{6}$. This is different from the well-known recrystallization mechanism of conventional alloys.

To the observed changes on the recovery and recrystallization process must be added the necessary investigation of the influence of the deformation mode. Compressive deformation activates the dislocation slip deformation which inhibits SIM and/or detwinning of B19 ${ }^{17}$.

The present work investigates the mechanisms associated with the recovery of a NiTi superelastic alloy submitted to uniaxial compression in comparison with recovery in conventional alloys.

The use of compression deformation, the annealing at several temperatures for short times with the purpose of observing the initial stages of recovery, as well as the use of EBSD (Electron Backscattered Diffraction) and instrumented ultramicrohardness techniques, provide originality and relevance to this work.

\section{Experimental}

The present work used a NiTi (51.54 at \% Ni) ingot made in the Instituto Tecnológico da Aeronáutica (ITA) by Vacuum Induction Melting (VIM). The ingot was cut and submitted 
to Vacuum Arc Remelting (VAR) in a copper crucible so that the pieces were small enough that hot forging could be performed.

The pieces were submitted to hot forging at $800{ }^{\circ} \mathrm{C}$ in order to obtain cylinders with $8 \mathrm{~mm}$ diameter. The cylinders were cut into small samples (10 $\mathrm{mm}$ high) using a precision diamond saw. The samples were solubilized at $950^{\circ} \mathrm{C}$ for $2 \mathrm{~h}$, followed by quenching in water and labeled as EQS. Some of these samples were submitted to uniaxial compression (up to $18 \%$ strain) for stabilization of the B19' phase by dislocation slip and labeled as EQSC. Some of the EQSC samples were cut into smaller samples ( $3 \mathrm{~mm}$ high) and submitted to $30 \mathrm{~min}$ annealing at four different temperatures: $150^{\circ} \mathrm{C}$ (EQSC150), $200{ }^{\circ} \mathrm{C}$ (EQSC200), $250^{\circ} \mathrm{C}$ (EQSC250), $300^{\circ} \mathrm{C}$ (EQSC300). These samples were water quenched and then submitted to grinding (240 to 1500 mesh) and electrolytic polishing on methanol and sulfuric acid $20 \%$ solution $(25 \mathrm{~V}, 0.8 \mathrm{~A}, 30 \mathrm{~s})$. The orientation map was obtained by Electron Backscattered Diffraction (EBSD) on a Scanning Electronic Microscope (SEM) equipped with a lanthanum hexaboride $\left(\mathrm{LaB}_{6}\right)$ filament the following scanning parameters: $20 \mathrm{kV}$, Spot Size 550 , work distance $21 \mathrm{~mm}$, magnification $2000 \times$ and step size 1 $\mu \mathrm{m}$. The X-ray diffraction was performed using the following parameters: $\mathrm{Cu}-\mathrm{K} \alpha$ radiation, $40 \mathrm{kV}, 40 \mathrm{~mA}$, step $0.02^{\circ}$ and acquisition time $0.6 \mathrm{~s}$ per point. The mechanical properties were evaluated by Vickers instrumented ultramicrohardness, with the following conditions of load/unload: maximum load $\left(\mathrm{F}_{\text {max }}\right) 100 \mathrm{gf}(\sim 1000 \mathrm{mN})$, permanence time on maximum load of $20 \mathrm{~s}$, load/unload rate of $13.324 \mathrm{mN} / \mathrm{s}$. Each sample was submitted to 10 tests. These techniques provided a load $v s$ deep indentation graph and the following properties were calculated:

Classical Vickers hardness:

$$
H V=1.854 \frac{F_{\max }}{d}\left(\mathrm{~N} / \mathrm{mm}^{2}\right)
$$

where $F_{\text {max }}(\mathrm{N})$ is the maximum load and $d(\mu \mathrm{m})$ is the diagonal average after indenter removal.

Dynamic elastoplastic hardness:

$$
D H V 1=3.8584 \frac{F_{\max }}{h_{\max }^{2}}\left(\mathrm{mN} / \mu \mathrm{m}^{2}\right)
$$

were $h_{\max }(\mu \mathrm{m})$ is the maximum indentation depth before indenter removal.

Dynamic plastic hardness:

$$
D H V 2=3.8584 \frac{F_{\max }}{h_{r}^{2}}\left(\mathrm{mN} / \mu \mathrm{m}^{2}\right)
$$

where $h_{r}(\mu \mathrm{m})$ is the tangent to the unload curve.

Recovery energy fraction: $N i t=\left(\frac{E_{r}}{E_{t}}\right) 100 \%$

where $E_{r}$ is the area under the unload curve and $E_{t}$ is the area under the load curve.

\section{Results and Discussion}

The starting material was the EQS samples defined in the previous section. The samples were submitted to EBSD to obtain the orientation map of the B2 phase. The black spots in Figure 1a were identified by EDS as titanium carbide (TiC). Carbon is a contaminant for these alloys, coming from the graphite crucible ${ }^{8}$ of the vacuum induced melting (VIM) process.

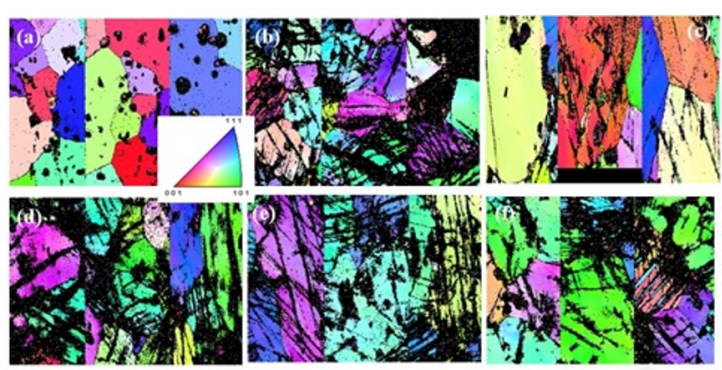

Figure 1. EBSD results, at room temperature, presented as maps of crystallographic orientations in reverse pole figures. (a) EQS, (b) EQSC, (c) EQSC150, (d) EQSC200, (e) EQSC250, (f) EQSC300.

The solubilized and compressed samples (EQSC) did not present the stress induced martensitic (SIM) plateau (Fig. 2). The compression curve showed three successive steps ${ }^{7}$ :

i) B2 elastic deformation;

ii) Stress induced martensitic transformation and detwinning;

iii) Plastic deformation by slip dislocation of $\mathrm{B} 2$ and B19' detwinning.

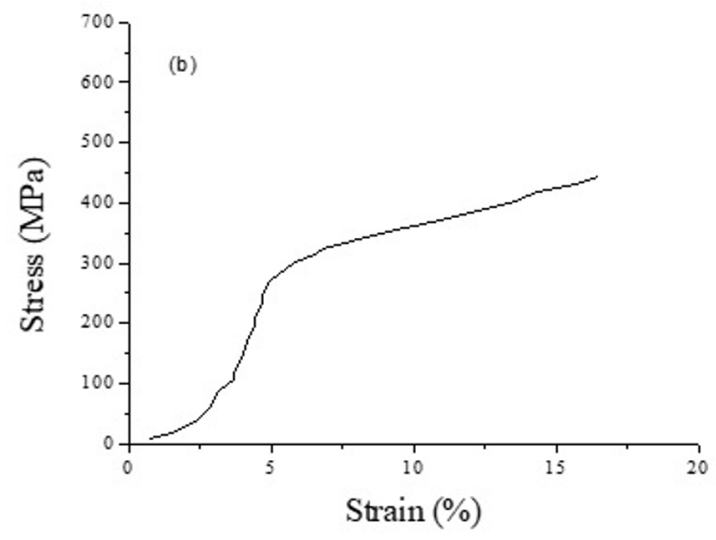

Figure 2. Stress-strain curve on uniaxial compression at room temperature.

The presence of the B19' phase in the EQSC samples was revealed by X-ray diffraction (Fig. 3b). In the EBSD image (Fig. 1b), the residual B2 regions show a nonuniform coloration due to residual stresses from work hardening. 
These stresses are also responsible for a decrease in the confidence index (Fig. 4) relative to its value in a strain free B2 lattice. The presence of a phase with lesser elastic rigidity (B19') leads to a decrease of the dynamic elastoplastic hardness reduction (DHV-1) relative to its value in EQS samples (Fig. 5).

In the case of the samples annealed at $150^{\circ} \mathrm{C}(\mathrm{EQSC} 150)$, the heat treatment led to a phase transformation to the high temperature phase (B2), although the dislocation density was still too high for the martensitic transformation (B2 $\rightarrow$ $\mathrm{R}$ or B2 $\rightarrow$ B19') to occur on cooling to room temperature. Stabilization of the high temperature phase is evidenced by the large fraction of the B2 phase in the EQSC150 samples, according to EBSD measurements (Fig. 4), which is reflected by the increase of DHV-2 (Fig. 6) relative to the EQSC sample, since the B19' phase present in the EQSC phase is softer than the B2 phase. The increase of Nit (Fig. 4) and the decrease of the dynamic plastic hardness DHV-2 (Fig. 6) relative to the EQS and EQSC samples are attributed to the beginning of the recovery process.

In the case of samples annealed at $200{ }^{\circ} \mathrm{C}$ (EQSC200), the recovery process is enhanced, leading to further increase of Nit (Fig. 4) and decrease of DHV-2, as well as an increase of HV and DHV-1 (Figure 5) and a decrease in the volume
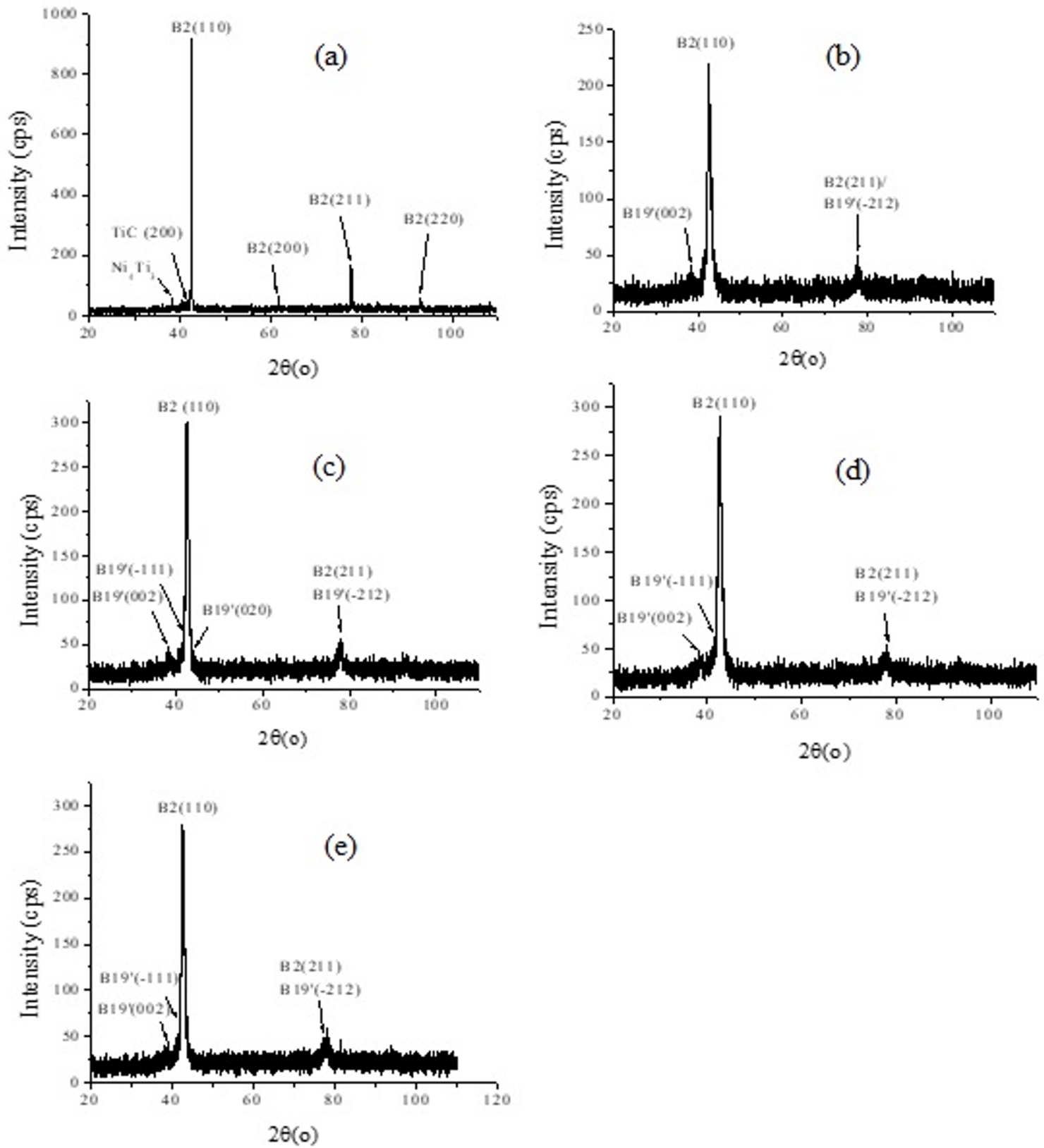

Figure 3. X ray diffraction patterns of (a) EQS, (b) EQSC, (c) EQSC150, (d) EQSC200, (e) EQSC250 samples. 


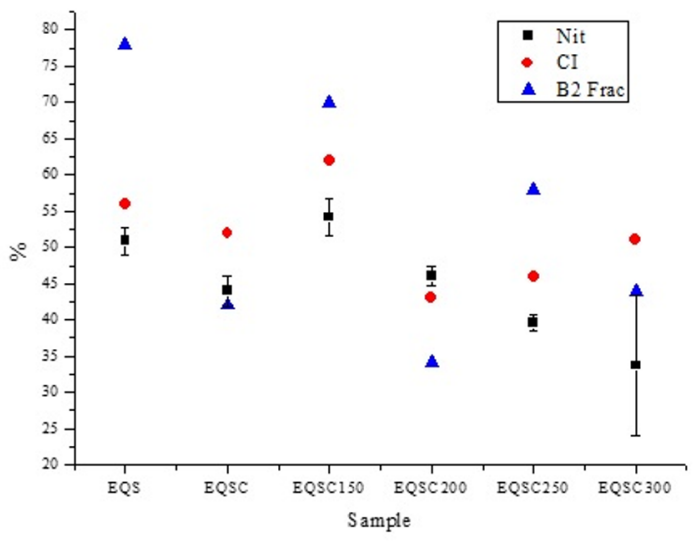

Figure 4. Confidence index (CI), B2 fraction and recovery energy (Nit) for the different kinds of samples studied in this work.

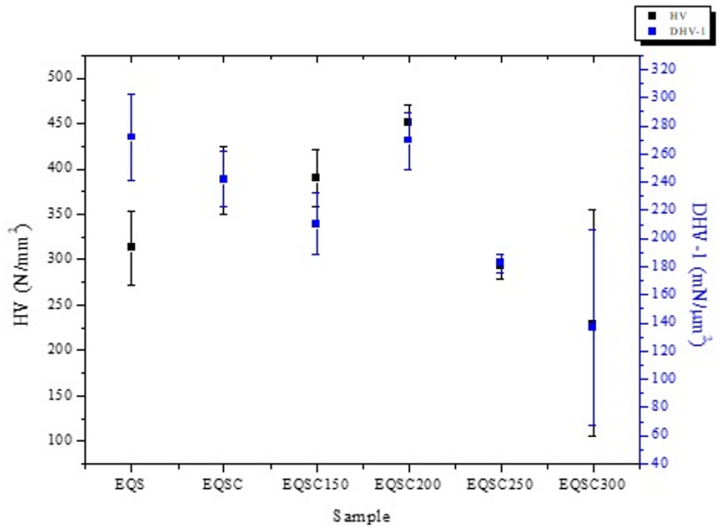

Figure 5. Penetration strength (classical Vickers hardness) and dynamic elastoplastic hardness for the different kinds of samples studied in this work.

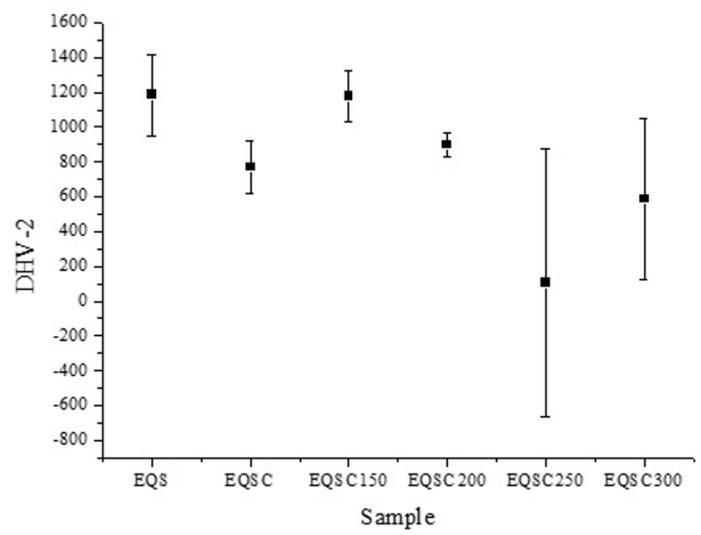

Figure 6. Dynamic plastic hardness (DHV-2) for the different kinds of samples studied in this work.

fraction of the $\mathrm{B} 2$ phase, as shown in the EBSD results (Fig. 1c). This suggests that the new phase is harder than the B2 phase $^{8}$. Previous studies ${ }^{9}$ suggest that annealing produces a two-step transformation of the form $\mathrm{B} 2 \rightarrow \mathrm{R} \rightarrow \mathrm{B} 19^{\prime}$, were $\mathrm{R}$ is a phase that forms close to room temperature.
This two-step transformation is due to presence of stress fields caused by slip dislocation that act as a barrier to the direct transformation $\left.\mathrm{B} 2 \rightarrow \mathrm{B} 19^{\prime}\right)$. It is hard observe the $\mathrm{R}$ by $\mathrm{X}$ - ray diffraction ${ }^{10}$ because the diffraction peaks of the $\mathrm{R}$ phase are very close to those of the $\mathrm{B} 2$ phase.

It is worth noticing that the uniaxial compression yielded a mix of work hardened B2 and B19' phases (Figure 3b). This can be understood as follows: B2 grains favorably oriented are directly transformed to the B19' phase, while in other grains elastic deformation leads to dislocation slip. Thus, B19' grains are less work hardened than the others. Therefore, the recovery process puts in evidence the greater capacity of B19' grains to undergo phase transformation. This hypothesis is supported by low confidence index in the remaining B2 phase of EQSC200 (Figure 4), suggesting a larger work hardening.

In the case of samples annealed at $250^{\circ} \mathrm{C}(\mathrm{EQSC} 250)$, the values of HV and DHV-1 are still lower (Fig. 5). This is attributed to a further increase of the volume fraction of the $\mathrm{B} 2$ phase due to recovery relative to samples annealed at $200^{\circ} \mathrm{C}$.

Finally, in the case of samples annealed at $300{ }^{\circ} \mathrm{C}$ (EQSC300), the values of $\mathrm{HV}$ and DHV-1 continue to decrease (Fig. 5), but there is a large standard deviation for both parameters. The EBSD results show a reduction of the volume fraction of the B2 phase (Fig. 1f) and an increase in the value of CI (Figure 4). Remembering that the sample consists of $\mathrm{B} 2$ and $\mathrm{B} 19$ 'phases stabilized by slip dislocation, these results suggest the occurrence of recrystallization following the recovery observed at lower temperatures. Grains that do not favor stress induced transformation accumulate larger strain energy and thus possess a higher driving force to recrystallization than the other grains.

\section{Conclusion}

The present study studied the recovery phenomenon on a NiTi superelastic alloy solubilized, compressed and aged, based on EBSD microstructural evidences and instrumented ultramicrohardness measurements.

The solubilized and compressed samples did not present the stress induced martensitic plateau and consisted of strain hardened B2 and B19'phases.

The first recovery response was the reverse transformation $\mathrm{B} 19^{\prime} \rightarrow \mathrm{B} 2$ in samples annealed at $150{ }^{\circ} \mathrm{C}$ with the $\mathrm{B} 2$ stabilized at room temperature by strain hardening.

In samples annealed at $200^{\circ} \mathrm{C}$, the recovery process was enhanced and the results suggested a two-stage transformation of the form B19' $\rightarrow \mathrm{R} \rightarrow \mathrm{B} 2$ with an increase of $\mathrm{HV}$ and DHV-1 and a decrease in the volume fraction of the $\mathrm{B} 2$ phase.

A significant microstructural restoration was observed in samples annealed at $250^{\circ} \mathrm{C}$, with an increase in the volume fraction of the $\mathrm{B} 2$ phase and a decrease in the values of $\mathrm{HV}$ and DHV-1 relative to samples annealed at lower temperatures. 
In samples annealed at $300^{\circ} \mathrm{C}$, the large standard deviation of the results suggests a heterogenous behavior that may be due to a mix of recovery and recrystallization.

\section{Acknowledgments}

The authors thank Instituto de Tecnologia da Aeronáutica (ITA) for providing the raw material used in this work.

FMBF acknowledges funding by National Funds through the Portuguese Foundation for Science and Technology (FCTMCTES), Reference UID/CTM/50025/2013, and FEDER funds through the COMPETE 2020 Programme under project POCI-01-0145-FEDER-007688. ASP acknowledges CNPq/ Brazil research productivity scholarship PQ-2 - Process 307798/2015-1.

\section{References}

1. Otsuka K, Wayman CM, eds. Shape Memory Materials. New York: Cambridge University Press; 1998.

2. Bhattacharya K, Conti S, Zanzotto G, Zimmer J. Crystal symmetry and the reversibility of martensitic transformations. Nature. 2004;428:55-59.

3. Nishida M, Ii S, Kitamura K, Furukawa T, Chiba A, Hara T, et al. New deformation twinning mode of B19' martensite in Ti-Ni shape memory alloy. Scripta Materialia. 1998;39(12):1749-1754.
4. Kazemi-Choobi K, Khalil-Allafi J, Abbasi Chianeh V. Investigation of the recovery and recrystallization processes of $\mathrm{Ni}_{50.9} \mathrm{Ti}_{49.1}$ shape memory wires using in situ electrical resistance measurement. Materials Science and Engineering: A. 2012;551:122-127.

5. Prokoshkin SD, Brailovski V, Inaekyan KE, Demers V, Khmelevskaya IY, Dobatkin SV, et al. Structure and properties of severely cold-rolled and annealed Ti-Ni shape memory alloys. Materials Science and Engineering: A. 2008;481-482:114-118.

6. Khelfaoui F, Thollet G, Guenin G. Microstructural evolution kinetics after plastic deformation of equiatomic Ti-Ni alloy during isothermal annealings. Materials Science and Engineering: $A$. 2002;338(1-2):305-312.

7. Liu Y, Xie Z, Van Humbeek J, Delaey L. Asymmetry of stressstrain curves under tension and compression for NiTi shape memory alloys. Acta Materialia. 1998;46(12):4325-4338.

8. Chiang LJ, Li CH, Hsu YF, Wang WH. Age-induced four-stage transformation in Ni-rich NiTi shape memory alloys. Journal of Alloys and Compounds. 2008;458(1-2):231-237.

9. Aboutalebi MR, Karimzadeh M, Salehi MT, Abbasi SM, Morakabati $M$. Influences of aging and thermomechanical treatments on the martensitic transformation and superelasticity of highly Ni-rich Ti-51.5 at.\% Ni shape memory alloy. Thermochimica Acta. 2015;616:14-19.

10. Arciniegas M, Casals J, Manero JM, Peña J, Gil FJ. Study of hardness and wear behavior of NiTi shape memory alloys. Journal of Alloys and Compounds. 2008;460(1-2):213-219. 